\section{General practice characteristics and chest X-ray rate}

Thank you for your comprehensive article detailing the research study, ${ }^{1}$ but as you mentioned at the end of your article: 'Indeed, O'Dowd et al found no reduction in deaths within 90 days of diagnosis in practices that had higher utilisation of $C X R$ [chest X-ray].

I am not sure that you have proved your assertion that just increasing the numbers of chest $X$-rays in general practice will improve the rate of lung cancer diagnoses. Did you look at diagnosed lung cancer case rates in the various practices involved in your study?

Perhaps targeted low-dose CT screening scans in high-risk populations would be more effective in increasing the numbers of early diagnoses of this devastating disease?

Sarah C Hildebrand,

GP, Tile House Surgery, Brentwood.

Email: sarahhildebrandanhs.net

\section{REFERENCE}

1. Bradley SH, Barclay M, Cornwell B, et al. Associations between general practice characteristics and chest X-ray rate: an observational study. Br J Gen Pract 2022; DOI: https://doi.org/10.3399/BJGP.2021.0232.

\section{DOI: https://doi.org/10.3399/bjgp22X718589}

\section{Author response}

Many thanks for reading our paper Associations between general practice characteristics and chest X-ray rate' and for your comments.

In the paper we discuss some of the evidence around numbers of chest $X$-rays requested by GPs and lung cancer outcomes. We noted that, although we feel that it is plausible that increasing the number of chest $X$-rays requested for patients who have symptoms who are at risk of lung cancer could improve outcomes, the evidence base regarding this remains equivocal. We agree that the research presented in our paper would not warrant a definitive assertion that increasing numbers of chest $X$-rays performed in general practice improves outcomes. While we feel such an association is plausible, and discussed evidence that suggests that increasing frequency of chest $X$-ray investigations in patients who have symptoms may contribute to earlier-stage diagnosis, ${ }^{1}$ we did not assert that such an association exists.

The study examined the numbers of chest X-rays performed in relation to characteristics of practices and their populations. The study did not include data on cancer outcomes, therefore we would not have been able to prove any effect on outcomes caused by differences in chest X-ray rates, and this was not an objective of the study. However, we agree this is an important research question and we are planning to undertake a study that does examine chest $X$-ray rates of general practices in relation to lung cancer outcomes.

We agree that screening of asymptomatic patients using low-dose CT will have an increasingly important role in lung cancer detection over the coming years. However, because less than half of all patients with lung cancer fulfil eligibility criteria for screening, ${ }^{2}$ and even among those eligible only about half will attend, ${ }^{3}$ screening will only ever detect a small proportion of lung cancers overall. Thus, even if CT screening for lung cancer is rolled out in the UK and elsewhere, the role of GPs in detecting symptomatic disease will remain crucial.

Stephen Bradley, on behalf of the authors,

Clinical Research Fellow, Leeds Institute of Health Sciences, University of Leeds, Leeds.

Email: medsbralaleeds.ac.uk

\section{REFERENCES}

1. Kennedy MPT, Cheyne L, Darby M, et al. Lung cancer stage-shift following a symptom awareness campaign. Thorax 2018; 73(12): 1128-1136.

2. Gracie K, Kennedy MPT, Esterbrook G, et al. The proportion of lung cancer patients attending UK lung cancer clinics who would have been eligible for low-dose CT screening. Eur Respir J 2019; 54(2): 1802221. DOI: 10.1183/13993003.02221-2018.

3. Quaife SL, Ruparel M, Dickson JL, et al. Lung Screen Uptake Trial (LSUT): randomized controlled clinical trial testing targeted invitation materials. Am J Resp Crit Care Med 2020; 201(8): 965-975. DOI: 10.1164/rccm.201905-09460C.

DOI: https://doi.org/10.3399/bjgp22X718601

\section{Non-speculum sampling for cervical screening}

We were saddened to read about Ms Wishart's experiences with screening and how she has felt let down by the NHS Cervical Screening Programme. ' Several of us have worked in or with the Cervical Screening Programme for many years and acknowledge that there are issues around some women finding speculum examinations difficult and painful. The professional bodies, charities, and indeed the screening programme have striven to establish and maintain high standards. But clearly these have not always been achieved. We agree that training and communication are key, including as Ms Wishart states, a personalised and empathetic approach.

As researchers we are hopeful that collecting samples without need for a speculum will help make cervical screening easier for individuals who have found it to be difficult or traumatic. We thank Ms Wishart for sharing her experiences and helping to raise awareness about this important issue.

Anita W Lim, on behalf of the authors,

Senior Research Fellow, King's College London, London.

Email: anita.limakcl.ac.uk

\section{Competing interests}

Anita W Lim declares non-financial support from Copan Italia and Roche outside of the submitted work and receiving payment from Roche for giving a talk outside of the submitted work.

\section{REFERENCE}

1. Wishart LM. Non-speculum sampling for cervical screening in older women. [Letter]. Br J Gen Pract 2022; DOI: https://doi.org/10.3399/bjgp22X718313.

DOI: https://doi.org/bjgp22X718613

\section{Correction}

Helen J Curtis, Peter Inglesby, Caroline E Morton, et al (The OpenSAFELY Collaborative). Br J Gen Pract 2022; DOI: https://doi.org/10.3399/BJGP.2021.0376. The title of the article has been corrected to: Trends and clinical characteristics of COVID-19 vaccine recipients: a federated analysis of 57.9 million patients' primary care records in situ using OpenSAFELY.

DOI: https://doi.org/10.3399/bjgp22X718805 